\title{
Fixed low-dose ultrasound-assisted catheter-directed thrombolysis for intermediate and high-risk pulmonary embolism
}

\author{
Rolf P. Engelberger ${ }^{1 \dagger}$, Aris Moschovitis ${ }^{2 \dagger}$, Jennifer Fahrni ${ }^{1}$, Torsten Willenberg ${ }^{1}$, \\ Frederic Baumann', Nicolas Diehm¹, Do-Dai Do', Iris Baumgartner', \\ and Nils Kucher ${ }^{1,2 *}$
}

${ }^{1}$ Clinic for Angiology, Inselspital—University Hospital and University of Bern, Bern, Switzerland; and ${ }^{2}$ Clinic for Cardiology, Swiss Cardiovascular Center, Inselspital—University Hospital and University of Bern, Bern, Switzerland

Received 29 June 2013; revised 29 September 2013; accepted 18 October 2013; online publish-ahead-of-print 13 December 2013

This paper was guest edited by Brahmajee Nallamothu (University of Michigan; bnallamo@umich.edu)

Aims

No standardized local thrombolysis regimen exists for the treatment of pulmonary embolism (PE). We retrospectively investigated efficacy and safety of fixed low-dose ultrasound-assisted catheter-directed thrombolysis (USAT) for intermediate- and high-risk PE.

Methods and results

Fifty-two patients ( $65 \pm 14$ years) of whom 14 had high-risk PE (troponin positive in all) and 38 intermediate-risk PE (troponin positive in 91\%) were treated with intravenous unfractionated heparin and USAT using $10 \mathrm{mg}$ of recombinant tissue plasminogen activator per device over the course of $15 \mathrm{~h}$. Bilateral USAT was performed in $83 \%$ of patients. During 3-month follow-up, two [3.8\%; 95\% confidence interval (Cl) $0.5-13 \%]$ patients died (one from cardiogenic shock and one from recurrent PE). Major non-fatal bleeding occurred in two $(3.8 \% ; 95 \% \mathrm{Cl}, 0.5-13 \%)$ patients: one intrathoracic bleeding after cardiopulmonary resuscitation requiring transfusion, one intrapulmonary bleeding requiring lobectomy. Mean pulmonary artery pressure decreased from $37 \pm 9 \mathrm{mmHg}$ at baseline to $25 \pm 8 \mathrm{mmHg}$ at $15 \mathrm{~h}(P<0.001)$ and cardiac index increased from $2.0 \pm 0.7$ to $2.7 \pm 0.9 \mathrm{~L} / \mathrm{min} / \mathrm{m}^{2}(P<0.001)$. Echocardiographic right-to-left ventricular enddiastolic dimension ratio decreased from $1.42 \pm 0.21$ at baseline to $1.06 \pm 0.23$ at $24 \mathrm{~h}(n=21 ; P<0.001)$. The greatest haemodynamic benefit from USAT was found in patients with high-risk PE and in those with symptom duration $<14$ days.

Conclusion A standardized catheter intervention approach using fixed low-dose USAT for the treatment of intermediate- and highrisk PE was associated with rapid improvement in haemodynamic parameters and low rates of bleeding complications and mortality.

Keywords Pulmonary embolism • Catheter-directed thrombolysis • Cardiac output • Pulmonaryartery pressure • Mortality - Bleeding

\section{Introduction}

Pulmonary embolism (PE) is a common clinical condition with a large spectrum of outcomes. ${ }^{1}$ Patients can be stratified into different risk groups according to haemodynamic status and imaging or biomarker assessment of right ventricular function. ${ }^{2,3}$ Haemodynamically stable patients without signs of right ventricular dysfunction have an excellent short-term prognosis and are classified as low-risk PE patients. On the other hand, intermediate-risk (or submassive) PE, defined as PE with preserved systemic arterial pressure, but evidence of right ventricular dysfunction on imaging or biochemical assay, is associated with a 3-month mortality rate of $3-15 \% .^{2-5}$ The in-hospital mortality rate may exceed $50 \%$ in patients with high-risk (or massive) PE, defined as PE with sustained systemic arterial

† R.P.E and A.M. contributed equally to the present work.

* Corresponding author: Venous Thromboembolism Research Group, Clinics for Angiology and Cardiology, Swiss Cardiovascular Center, University Hospital Bern, 3010 Bern, Switzerland. Tel: +4131632 7963, fax: +4131632 4380, Email: nils.kucher@insel.ch

Published on behalf of the European Society of Cardiology. All rights reserved. C The Author 2013. For permissions please email: journals.permissions@oup.com 
hypotension, cardiogenic shock, or the need for cardiopulmonary resuscitation. ${ }^{6}$ While revascularization strategies such as systemic thrombolysis, surgical embolectomy, or catheter-based techniques are accepted treatment options for patients with high-risk PE, their use remains controversial in patients with intermediate-risk $P E$, and they are clearly not indicated in patients with low-risk PE. 3,7,8

Ultrasound-assisted catheter-directed thrombolysis (USAT) combines conventional catheter-directed thrombolysis (CDT) with a catheter system that uses high-frequency, low-power ultrasound. ${ }^{7}$ Ultrasound itself cannot dissolve thrombus. According to in vitro experiments, it causes reversible disaggregation of uncrosslinked fibrin fibers which may increase the thrombus permeability for thrombolytic drugs. In addition, the penetration of thrombolytic drugs into the thrombus may be increased by ultrasound pressure waves. ${ }^{9,10}$ In a non-randomized, retrospective study of 25 patients with high-risk PE, USAT provided better thrombus removal, and both thrombolytic infusion time and treatment-related complications were reduced compared with CDT alone. ${ }^{11}$ In two recent retrospective studies, USAT with varying drug doses and infusion times improved right ventricular enlargement assessed by chest computed tomography $(\mathrm{CT})^{12}$ and pulmonary artery pressures. ${ }^{13}$ However, no standardized local thrombolysis regimen exists for the treatment of PE. The purpose of this retrospective study was to assess haemodynamic and clinical outcomes in patients with highand intermediate-risk PE treated with a fixed low-dose USAT regimen.

\section{Methods}

\section{Study design and patients}

We performed a retrospective cohort study of patients treated by a standardized USAT protocol for PE at the Bern University Hospital in Switzerland between April 2010 and January 2013. Patients were eligible for USAT if they had high- or intermediate-risk PE and evidence of embolus located in at least one main or lower lobe pulmonary artery as assessed by contrast-enhanced chest CT or conventional pulmonary angiography. During the study period, $67 \mathrm{PE}$ patients (46 at intermediate risk and 21 at high risk) were eligible of whom 7 intermediate-risk patients were managed medically and 1 by surgical embolectomy, and 6 high-risk patients underwent surgical embolectomy and 1 received systemic thrombolysis. Overall, 38 intermediate-risk patients and 14 high-risk patients were treated by USAT. Patients signed informed consent for retrospective data collection.

High-risk PE was defined according to the American Heart Association as PE with sustained hypotension (systolic blood pressure $<90 \mathrm{mmHg}$ for at least $15 \mathrm{~min}$ or requiring inotropic support, not due to any cause other than PE), pulselessness, or persistent profound bradycardia (heart rate $<40$ b.p.m. with signs or symptoms of shock). ${ }^{3}$ Intermediaterisk PE was defined as PE with preserved systemic systolic blood pressure $(\geq 90 \mathrm{mmHg})$ and evidence of right ventricular dysfunction on imaging. ${ }^{3}$ A right-to-left ventricular end-diastolic diameter ratio (RV/LV ratio) of $>0.9$ on echocardiography or multi-detector contrastenhanced CT was used to confirm the presence of right ventricular dysfunction. $2,3,5,14$

Medical records were reviewed and clinical data including symptoms, vital signs, comorbidities, risk factors for venous thrombo-embolism, and common laboratory values were recorded. Symptom duration was classified as acute, subacute, and acute-on-chronic. Acute PE refers to PE for which suggestive symptoms have been present for less than 14 days, subacute $\mathrm{PE}$ as symptom duration of $14-28$ days, and acute-on-chronic PE refers to $P E$ in patients with a previous history of symptoms suggestive of $\mathrm{PE}$ and acute exacerbation of symptoms within the last 14 days. Multidetector contrast-enhanced CT images were used to determine the RV/ LV ratio and the modified Miller score at baseline. ${ }^{12,15}$ This scoring system is based on the number of segmental pulmonary arteries involved. Nonocclusive thrombus in a segmental artery is assigned a score of 1 , occlusive thrombus a score of 2 . Thrombus in more proximal arteries receives a score equal to the number of segmental arteries supplied, with a maximal score of 36 points if the main pulmonary trunk is completely occluded. ${ }^{15}$ Transthoracic echocardiography was performed at baseline and after the completion of USAT at $24 \mathrm{~h}$. Recorded echocardiographic loops were analysed by an experienced cardiologist (A.M.) for signs of right ventricular dysfunction, and graded as normal RV function, or mildly, moderately, or severely reduced RV function. ${ }^{16}$ Right and left ventricular dimensions were obtained from an end-diastolic apical fourchamber image by measuring the ventricular endocardial borders at the sub-annular plane located $1 \mathrm{~cm}$ above the annular plan and perpendicular to the interventricular septal axis.

\section{Standardized procedure of ultrasound-assisted catheter-directed thrombolysis}

All patients were treated with USAT using 12-cm treatment zone EkoSonic MACH4 Endovascular Systems (EKOS Corporation; Bothell, WA, USA). ${ }^{12}$ The EkoSonic Endovascular System consists of three main components: an Intelligent Drug Delivery Catheter (IDDC); a removable MicroSonic Device (MSD) containing multiple small ultrasound transducers distributed along the $12-\mathrm{cm}$ long treatment zone; and the EkoSonic control unit. The MSD is placed through the central lumen of the IDDC to deliver high-frequency $(2.2 \mathrm{GHz})$ and low-energy ( 0.5 Watt per transducer) ultrasound. The EkoSonic control unit provides power to the system and the user interface for operator control. It continuously adjusts the administered ultrasound energy according to the temperature at the treatment zone measured by the thermocouples within the IDDC. The EkoSonic Endovascular System was cleared by the US FDA in 2008 for the infusion of solutions into the pulmonary arteries and is C.E. certified for intravascular applications.

All patients received an intravenous bolus of unfractionated heparin of 80 units per kilogram body weight at initial presentation. The insertion of the catheter system was performed at the cardiac catheterization laboratory with continuous haemodynamic and electrocardiographic monitoring. Venous access was obtained at the right common femoral vein using a 6-French introducer sheath for patients who were scheduled for unilateral EkoSonic device placement or a 10-French double-lumen introducer sheath for those who were scheduled for bilateral EkoSonic device insertion. In five patients with concomitant ilio-femoral deep vein thrombosis, the contralateral common femoral vein was used for venous access. Invasive pressure tracings and a blood sample for the mixed venous oxygen saturation were obtained from the main pulmonary artery. Systemic arterial oxygen saturation was recorded through transcutaneous oxygen saturation measurement. A 0.035 -inch hydrophilic guidewire (Terumo Corporation, Tokyo, Japan) and a standard 5-French multipurpose angiographic catheter were used to cross the embolic occlusion. To minimize the risk of pulmonary artery perforation, only the main and lower lobe pulmonary arteries were considered for catheter insertion. With the guidewire tip in a safe position within a large lower lobe segmental branch, the angiographic catheter was exchanged for the EkoSonic IDDC. Finally, the guidewire was removed and the MSD containing the ultrasound transducers was inserted into the IDDC. Bilateral device placement was performed in case of embolus located in both main and proximal lower lobe pulmonary arteries. 
Per discretion of the interventional physician, a bolus of recombinant tissue plasminogen activator (rt-PA) of up to $5 \mathrm{mg}$ per device was allowed but discouraged for patients with intermediate-risk PE. A continuous infusion of rt-PA at $1 \mathrm{mg} / \mathrm{h}$ and of saline coolant at $35 \mathrm{~mL} / \mathrm{h}$ per catheter, and intravascular ultrasound delivery were then initiated. After catheter placement, patients were transferred to the intermediate or intensive care unit for continuous monitoring. After $5 \mathrm{~h}$ of treatment, the infusion rate of rt-PA was reduced to $0.5 \mathrm{mg} / \mathrm{h}$ per catheter for the remaining $10 \mathrm{~h}$. The maximum suggested $\mathrm{rt}-\mathrm{PA}$ dose was $20 \mathrm{mg}$ for patients who had not received a bolus and $30 \mathrm{mg}$ for those with bolus $(10 \mathrm{mg}$ bolus, $20 \mathrm{mg}$ infusion). During USAT, intravenous unfractionated heparin was continuously administered with repetitive dose adjustments every $6 \mathrm{~h}$ to achieve and maintain an activated partial thromboplastin time ratio of $1.5-2.5^{3}$

At $15 \mathrm{~h}$, the rt-PA infusion and ultrasound delivery were stopped. Thereafter, the EkoSonic devices were removed without fluoroscopic guidance in the intermediate or intensive care unit. After the removal of the MSD, invasive pressure tracings were recorded while slowly pulling back the EkoSonic IDDC. Once a typical pressure tracing of the main pulmonary artery trunk was obtained, a blood sample for the follow-up mixed venous oxygen saturation was taken from the IDDC. Follow-up systemic arterial oxygen saturation was obtained as described above. Finally, the EkoSonic IDDC and the introducer sheath were removed, and the puncture site manually compressed until local haemostasis was achieved.

\section{Endpoints and definitions}

The primary endpoints of this study were the change of pulmonary artery pressure and cardiac index from the time of catheter placement to catheter removal. Cardiac index was derived from dividing cardiac output (CO) by body surface area (BSA). Cardiac output was calculated with the following formula according to the Fick principle: ${ }^{17} \mathrm{CO}=\mathrm{VO}_{2} /$ $\left[13.4 \times \mathrm{Hb} \times\left(\mathrm{S}_{\mathrm{a}} \mathrm{O}_{2}-\mathrm{S}_{\mathrm{v}} \mathrm{O}_{2}\right)\right]$; where $\mathrm{VO}_{2}$ is the estimated oxygen uptake [calculated by: BSA $\times(161-$ age $\times 0.54)$ for men; and BSA $\times$ $(147.5$ - age $\times 0.47)$ for women]; Hb the haemoglobin level in $(g / d L)$, and $\mathrm{S}_{\mathrm{a}} \mathrm{O}_{2}$ and $\mathrm{S}_{\mathrm{v}} \mathrm{O}_{2}$ the oxygen saturation of arterial and venous blood, respectively. Body surface area was calculated according to the DuBois formula $\left[B S A=0.007184 \times\left(\right.\right.$ height $(\mathrm{cm})^{0.725} \times$ weight $\left.(\mathrm{kg})^{0.425}\right]$.

Secondary endpoints were treatment-related success rates and complications. Technical success was defined as successful insertion of the EkoSonic device and the initiation of the rt-PA infusion with simultaneous high-frequency/low-energy ultrasound energy delivery. Stabilization of haemodynamics was defined as: cardiogenic shock or hypotension resolved, vasopressor dose reduced or discontinued, or signs of RV failure on echocardiography improved within $24 \mathrm{~h}$ of the end of the procedure. Bleeding complications were classified according to the International Society on Thrombosis and Haemostasis, where major bleedings are either (i) fatal bleeding, (ii) symptomatic bleeding in a critical area or organ, such as intracranial, intraspinal, intraocular, retroperitoneal, intraarticular or pericardial, or intramuscular with compartment syndrome, and/or (iii) bleeding causing a drop in haemoglobin level of $\geq 2 \mathrm{~g} / \mathrm{dL}$, or leading to transfusion of two or more units of whole blood or red cells. ${ }^{18}$ Minor bleedings are less severe bleedings not included in the definition of major bleedings. ${ }^{18}$ After 3 months, the patient or their treating physician were contacted by telephone to assess intermediate clinical outcomes.

\section{Statistical analysis}

Data are presented as means \pm standard deviations or absolute numbers and percentages for continuous and categorical variables, respectively. Where appropriate, categorical outcomes are presented as percentage with $95 \%$ confidence intervals $(95 \% \mathrm{Cl})$. Data were stratified with regard to intermediate- and high-risk PE. P-values for differences between the groups were calculated from unpaired $t$-tests or Wilcoxon rank test where appropriate for continuous variables, and $\chi^{2}$ tests for categorical variables. Parameters assessed before and after US-assisted CDT were compared using paired $t$-tests. All statistical analyses were performed using STATA version 9.1 (Stata Corp., College Station, TX, USA).

\section{Results}

\section{Study population}

During the study period, a total of 52 patients with a mean age of $65 \pm 14$ years were treated (Table 1). High-sensitivity troponin $T$ levels were available in all patients with high-risk PE and in 34 patients with intermediate-risk PE. Fourteen (100\%) and 31 (91\%) of patients with high- and intermediate-risk PE had positive troponin levels (above the manufacturers cut-off), respectively. The duration of anticoagulation therapy prior to USAT was $<24 \mathrm{~h}$ in 46 (88\%) patients.

\section{Contrast-enhanced computed tomography}

Baseline contrast-enhanced CT examinations were available for analysis in 46 (88\%) patients. In four patients, CT examinations performed at an outside institution were not available, and in another two patients with suspected acute coronary syndrome, conventional pulmonary angiography was performed as first-line diagnostic imaging procedure. Modified Miller score at baseline contrastenhanced CT examination was $18.3 \pm 0.81$ for patients with high-risk $P E$ and $17.1 \pm 0.32$ for patients with intermediate-risk $P E(P=0.10)$. Mean right $(5.1 \pm 0.1 \mathrm{~cm}$ vs. $5.1 \pm 0.1 \mathrm{~cm} ; P=0.92)$ and left ventricular end-diastolic diameters $(3.4 \pm 0.2 \mathrm{~cm}$ vs. $3.7 \pm 01 \mathrm{~cm} ; P=$ 0.12) were similar between patients with high- and intermediate-risk $\mathrm{PE}$. The corresponding RV/LV ratio was higher in patients with highrisk $P E$ than in patients with intermediate-risk $P E(1.56 \pm 0.07$ vs. $1.42 \pm 0.03, P=0.048)$.

\section{Treatment details and complications}

In 11 (79\%) patients with high-risk PE and 32 (84\%) with intermediate-risk PE, EkoSonic catheters were inserted bilaterally, the remainder underwent unilateral catheter insertion. Technical success was achieved in all patients. A bolus of rt-PA during catheter insertion was administered in 4 (29\%) patients with high-risk and $3(8 \%)$ with intermediate-risk PE $(P=0.06)$, with higher bolus doses of rt-PA in patients with high-risk PE (mean $5.8 \mathrm{mg}$; Range $5-8 \mathrm{mg})$ vs. intermediate-risk PE $(2 \mathrm{mg}$ in all; $P=0.02)$. Total rt-PA dose per patient including bolus administration were similar between both groups, with $22.0 \pm 9.1 \mathrm{mg}$ for high-risk PE patients and $20.1 \pm 3.7 \mathrm{mg}$ for intermediate-risk PE patients $(P=0.30)$. Mean rt-PA dose per catheter was $11.8 \pm 5.1 \mathrm{mg}$, without a significant difference between patients with high-risk PE $(13.3 \pm 8.5 \mathrm{mg})$ and intermediate-risk $P E(11.3 \pm 3.1 \mathrm{mg}, P=0.23)$. Mean treatment duration was $15.6 \pm 2.7 \mathrm{~h}$ in high-risk PE patients and $15.4 \pm 1.2 \mathrm{~h}$ in intermediate-risk $P E$ patients $(P=0.12)$. 
Table I Patient characteristics, clinical presentation, and comorbidities/venous thrombo-embolism risk factors

\begin{tabular}{|c|c|c|c|c|}
\hline & $\begin{array}{l}\text { Total } \\
(n=52)\end{array}$ & $\begin{array}{l}\text { Intermediate-risk } \\
\text { PE }(n=38)\end{array}$ & $\begin{array}{l}\text { High-risk } \\
\text { PE }(n=14)\end{array}$ & $P$-value \\
\hline \multicolumn{5}{|l|}{ Demographics } \\
\hline Age (years) & $65 \pm 14$ & $69 \pm 12$ & $63 \pm 14$ & 0.14 \\
\hline Men & $33(64)$ & $26(68)$ & $7(50)$ & 0.22 \\
\hline Body mass index $\left(\mathrm{kg} / \mathrm{m}^{2}\right)$ & $29 \pm 5$ & $29 \pm 1$ & $28 \pm 1$ & 0.45 \\
\hline \multicolumn{5}{|l|}{ Symptom duration } \\
\hline Acute & $39(75)$ & $26(68)$ & $13(93)$ & 0.07 \\
\hline Subacute & $7(13)$ & $7(18)$ & $0(0)$ & 0.08 \\
\hline Acute-on-chronic & $6(12)$ & $5(13)$ & $1(7)$ & 0.55 \\
\hline \multicolumn{5}{|l|}{ Clinical presentation } \\
\hline Dyspnoea & $51(98)$ & $37(97)$ & $14(100)$ & 0.54 \\
\hline Tachypnoea $>20$ per min & $39(75)$ & $26(68)$ & $13(93)$ & 0.07 \\
\hline Tachycardia >100 b.p.m. & $35(67)$ & $23(61)$ & $12(86)$ & 0.09 \\
\hline Chest pain & $20(38)$ & $16(42)$ & $4(29)$ & 0.37 \\
\hline Syncope (fainting) & $19(37)$ & $11(29)$ & $8(57)$ & 0.06 \\
\hline Limb pain or swelling & $17(33)$ & $16(42)$ & $1(7)$ & 0.02 \\
\hline Transient hypotension without vasopressors ${ }^{\mathrm{a}}$ & $13(25)$ & $8(21)$ & $5(36)$ & 0.28 \\
\hline Dizziness or lightheadedness & $10(19)$ & $6(16)$ & $4(29)$ & 0.30 \\
\hline $\begin{array}{l}\text { Prolonged hypotension requiring multiple vasopressors to maintain } \\
\text { systolic pressure }>90 \mathrm{mmHg}\end{array}$ & $4(8)$ & $0(0)$ & $4(29)$ & - \\
\hline Active cardiopulmonary resuscitation & $3(6)$ & $0(0)$ & $3(21)$ & - \\
\hline Cardiac arrest & $3(6)$ & $0(0)$ & $3(21)$ & - \\
\hline Systolic pressure $<90 \mathrm{mmHg}$ despite vasopressors & $2(4)$ & $0(0)$ & $2(14)$ & - \\
\hline \multicolumn{5}{|l|}{ Risk factors and comorbidities } \\
\hline Systemic hypertension & $30(59)$ & $22(59)$ & $8(57)$ & 0.88 \\
\hline Obesity & $19(38)$ & $14(39)$ & $5(36)$ & 0.84 \\
\hline Previous venous thrombo-embolism & $18(37)$ & $13(36)$ & $5(38)$ & 0.88 \\
\hline Immobilization ${ }^{\mathrm{b}}$ ( $<3$ months) & $17(35)$ & $11(32)$ & $6(43)$ & 0.49 \\
\hline Recent hospitalization ( $<3$ months) & $17(35)$ & $10(28)$ & $7(54)$ & 0.09 \\
\hline Severe infection or sepsis ( $<3$ months) & $17(33)$ & $14(38)$ & $3(21)$ & 0.27 \\
\hline Dyslipidemia & $15(32)$ & $11(32)$ & $4(31)$ & 0.92 \\
\hline Coronary artery disease & $11(22)$ & $6(16)$ & $5(36)$ & 0.13 \\
\hline Congestive heart failure & $10(20)$ & $6(16)$ & $4(29)$ & 0.32 \\
\hline Diabetes & $10(20)$ & $7(19)$ & $3(21)$ & 0.88 \\
\hline Chronic renal failure & $10(20)$ & $7(19)$ & $3(21)$ & 0.88 \\
\hline Current smoking & $10(23)$ & $8(24)$ & $2(20)$ & 0.78 \\
\hline Chronic pulmonary disease & $8(16)$ & $5(14)$ & $3(21)$ & 0.51 \\
\hline Recent surgery ( $<4$ weeks) & $7(14)$ & $3(8)$ & $4(31)$ & 0.05 \\
\hline Peripheral artery disease & $7(15)$ & $4(12)$ & $3(23)$ & 0.33 \\
\hline Active cancer or treatment ( $<6$ months) & $5(10)$ & $4(11)$ & $1(7)$ & 0.69 \\
\hline Recent trauma $(<4$ weeks $)$ & $4(8)$ & $3(8)$ & $1(8)$ & 0.94 \\
\hline Hormone therapy $^{c}$ & $2(4)$ & $2(6)$ & $0(0)$ & 0.39 \\
\hline
\end{tabular}

Data presented as mean \pm SD or number (\%). percentages may vary due to missing data.

aSystolic blood pressure $<90 \mathrm{mmHg}$ for $<15 \mathrm{~min}$ not requiring vasopressors.

${ }^{b}$ Defined as bed ridden for $>72 \mathrm{~h}$, plaster cast, or long-distance travel of $>6 \mathrm{~h}$

${ }^{\mathrm{c}}$ Oral contraceptive pill, hormone replacement therapy or Tamoxifen use.

Major bleedings occurred in 2 (3.8\%; 95\% Cl, 0.5-13\%) patients. One patient with high-risk PE (7\%; $95 \% \mathrm{Cl}, 2-34 \%)$ had a major intrathoracic bleeding after CPR requiring 4 units of packed blood cells, and one patient with intermediate-risk PE (2.6\%; 95\% Cl, $0.1-$ $14 \%)$ had an intrapulmonary haematoma requiring surgical lower lobe resection 10 days after the procedure. Minor bleedings 
occurred in 11 (21\%; $95 \% \mathrm{Cl}, 11-34 \%)$ patients. Of those, 5 (35\%; $95 \% \mathrm{Cl}, 12-64 \%)$ were in patients with high-risk and 6 (16\%; $95 \%$ $\mathrm{Cl}, 6-31 \%)$ in patients with intermediate-risk PE $(P=.12)$. During hospitalization, two patients with high-risk PE died. The cause of death was irreversible cardiogenic shock in one and recurrent autopsyproved PE 7 days after successful USAT in the other patient. In one patient with intermediate-risk, acute-on-chronic PE, open surgical embolectomy with closure of a patent foramen ovale was performed 2 days after failed USAT. There were no deaths during follow-up, resulting in a 3-month mortality rate of $3.8 \%(95 \% \mathrm{Cl}, 0.5-13 \%)$. Mean duration of stay in the intensive care or intermediate care unit was $3.7 \pm$ 3.1 days, with $4.1 \pm 2.4$ days for high-risk PE patients and $3.5 \pm 3.2$ days for intermediate-risk $P E$ patients $(P=0.54)$.

\section{Hemodynamic parameters}

At completion of USAT at $15 \mathrm{~h}$, stabilization of haemodynamic parameters was achieved in $93 \%(95 \% \mathrm{Cl}, 66-100 \%)$ patients with highrisk PE vs. 94\% (95\% Cl, 81-99\%) patients with intermediate-risk PE $(P=0.83)$. Systolic, diastolic, and mean arterial blood pressure measurements were significantly lower before and after USAT in patients with high-risk than in those with intermediate-risk $P E(P<0.01$ for both time points), while the mean heart rate before and after USAT did not differ between the two groups $(P=0.07$ for before, and $P=0.33$ for after treatment) (Table 2).

Systolic, diastolic, and mean pulmonary artery pressure measurements significantly decreased after USAT (61 \pm 16 vs. $40 \pm$ $11 \mathrm{mmHg} ; 23 \pm 7$ vs. $16 \pm 6 \mathrm{mmHg}$; and $37 \pm 9$ vs. $25 \pm$ $8 \mathrm{mmHg} ; P<0.001$ for all) (Figure $1 A$ ). Pulmonary artery pressure measurements were not significantly different between high- and intermediate-risk PE patients, both before and after USAT (Table 2). The mean decrease in systolic $(-29 \pm 16$ vs. $-18 \pm 11$; $P=0.02)$ and mean $(-16 \pm 9$ vs. $-10 \pm 7 \mathrm{mmHg}$; $=0.042)$ pulmonary artery pressure from baseline to $15 \mathrm{~h}$ was greater in patients with high-risk PE compared with patients with intermediate-risk PE.
The presence of high-risk PE was the only predictor of improved pulmonary artery pressure. Mixed venous oxygen saturation increased from $58 \pm 12$ to $66 \pm 8 \%(P<0.001)$, with a similar increase from baseline to $15 \mathrm{~h}$ in patients with high- and intermediate-risk PE patients $(+11 \pm 13$ vs. $+6.5 \pm 8 \% ; P=0.25)$. Overall, cardiac index increased from $2.0 \pm 0.7$ to $2.7 \pm 0.9 \mathrm{~L} / \mathrm{min} /$ $\mathrm{m}^{2}(+34 \% ; P<0.001$; Figure $1 B)$, with a similar increase in patients with high-risk $\left(+0.83 \mathrm{~L} / \mathrm{min} / \mathrm{m}^{2} ;=+42 \%\right)$ and intermediate-risk $\mathrm{PE}\left(+0.66 \mathrm{~L} / \mathrm{min} / \mathrm{m}^{2} ;=+33 \% ; P=0.54\right)$. Patients with acute onset of symptoms had a greater increase in mean cardiac index than patients with subacute or acute-on-chronic presentation $(+0.8 \pm$ 0.7 vs. $\left.+0.3 \pm 0.5 \mathrm{~L} / \mathrm{min} / \mathrm{m}^{2}, P=0.054\right)$ but a similar decrease in mean pulmonary artery pressure $(-13 \pm 7$ vs. $-10 \pm 8 \mathrm{mmHg}$; $P=0.23)$ after USAT.

\section{Echocardiography}

Baseline echocardiography was available in 32 patients and follow-up echocardiography at $24 \mathrm{~h}$ in 33 patients; 21 patients had received both the baseline and the follow-up echocardiography. Among the 21 patients with baseline and follow-up echocardiography, baseline values for right $(5.2 \pm 0.4$ vs. $5.4 \pm 0.8 \mathrm{~cm} ; P=0.48)$ and left ventricular end-diastolic diameters $(3.6 \pm 0.6$ vs. $3.9 \pm 0.5 \mathrm{~cm} ; P=$ $0.25)$ were similar in patients with high-risk $P E$ and intermediate-risk $\mathrm{PE}$, respectively. After USAT at $15 \mathrm{~h}$, right ventricular end-diastolic diameters significantly decreased in both high-risk $(4.2 \pm 0.7 \mathrm{~cm}$, $P=0.01)$ and intermediate-risk PE patients $(4.9 \pm 0.97 \mathrm{~cm}, P=$ $0.001)$, and left ventricular end-diastolic diameter increased in both high-risk $(4.3 \pm 0.67 \mathrm{~cm}, P=0.02)$ and intermediate-risk $P E$ patients $(4.6 \pm 0.77 \mathrm{~cm}, P=0.001)$. Overall, RV/LV ratio decreased from $1.42 \pm 0.21$ to $1.06 \pm 0.23(P<0.001$; Figure $1 C)$; it decreased from $1.47 \pm 0.25$ to $0.98 \pm 0.11(P=0.006)$ in high-risk $P E$ patients and from $1.40 \pm 0.20$ to $1.06 \pm 0.23(P<0.001)$ in intermediaterisk $\mathrm{PE}$ patients. Mean change in $\mathrm{RV} / \mathrm{LV}$ ratio was similar in patients with acute onset of symptoms compared with patients with subacute

Table 2 Systemic and pulmonary artery haemodynamic parameters

\begin{tabular}{|c|c|c|c|c|c|c|}
\hline & \multicolumn{3}{|c|}{ Intermediate-risk PE $(n=38)$} & \multicolumn{3}{|c|}{ High-risk PE $(n=14)$} \\
\hline & Before & After & $P$-value & Before & After & $P$-value \\
\hline \multicolumn{7}{|l|}{ Systemic } \\
\hline Systolic pressure (mmHg) & $133 \pm 15$ & $130 \pm 19$ & 0.3 & $99 \pm 22$ & $103 \pm 34$ & 0.7 \\
\hline Diastolic pressure $(\mathrm{mmHg})$ & $85 \pm 13$ & $75 \pm 10$ & $<0.01$ & $59 \pm 18$ & $60 \pm 21$ & 0.9 \\
\hline Mean pressure $(\mathrm{mmHg})$ & $101 \pm 12$ & $93 \pm 10$ & $<0.01$ & $73 \pm 19$ & $73 \pm 23$ & 0.9 \\
\hline Heart rate (b.p.m.) & $96 \pm 14$ & $83 \pm 15$ & $<0.01$ & $100 \pm 15$ & $77 \pm 19$ & $<0.01$ \\
\hline \multicolumn{7}{|l|}{ Pulmonary artery } \\
\hline Systolic pressure (mmHg) & $60 \pm 15$ & $42 \pm 13$ & $<0.01$ & $66 \pm 19$ & $36 \pm 7$ & $<0.01$ \\
\hline Diastolic pressure (mmHg) & $22 \pm 7$ & $16 \pm 6$ & $<0.01$ & $24 \pm 5$ & $16 \pm 3$ & $<0.01$ \\
\hline Mean pressure $(\mathrm{mmHg})$ & $36 \pm 9$ & $26 \pm 9$ & $<0.01$ & $39 \pm 10$ & $23 \pm 3$ & $<0.01$ \\
\hline Mixed venous oxygen saturation (\%) & $60 \pm 10$ & $67 \pm 7$ & $<0.01$ & $51 \pm 18$ & $62 \pm 11$ & 0.06 \\
\hline \multicolumn{7}{|l|}{ Cardiac performance } \\
\hline Cardiac output (L/min) & $4.2 \pm 1.1$ & $5.5 \pm 1.6$ & $<0.01$ & $3.7 \pm 2.3$ & $5.2 \pm 2.0$ & $<0.01$ \\
\hline Cardiac index $\left(\mathrm{L} / \mathrm{min} / \mathrm{m}^{2}\right)$ & $2.1 \pm 0.5$ & $2.8 \pm 0.9$ & $<0.01$ & $1.9 \pm 1.0$ & $2.7 \pm 1.0$ & $<0.01$ \\
\hline
\end{tabular}

Data presented as mean $\pm \mathrm{SD}$. 


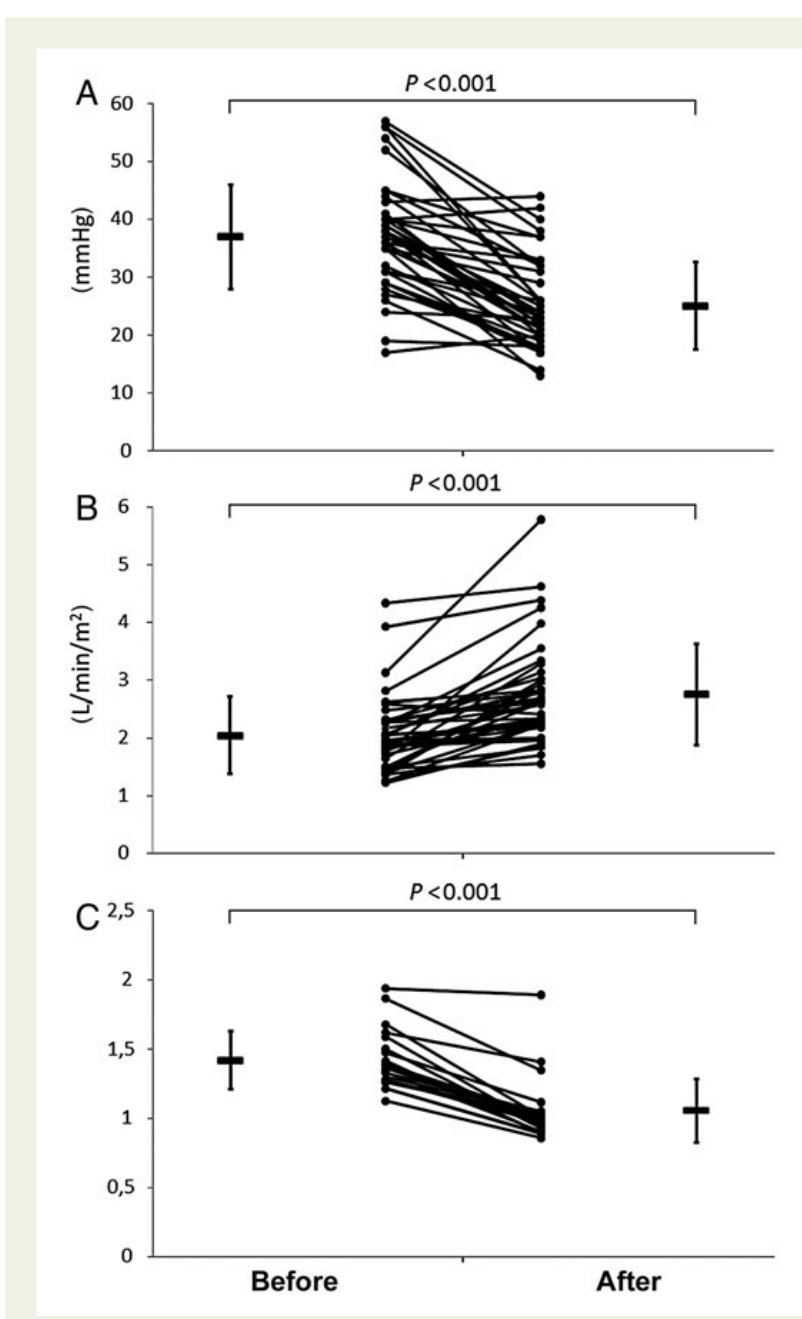

Figure I Paired chart of the mean pulmonary artery pressure $(A)$, cardiac index $(B)$, and echocardiographic RV/LV ratio $(C)$ before and after ultrasound-assisted catheter-directed thrombolysis. Individual responses and group mean \pm SD are shown. Note: two patients with mean pulmonary artery pressure below $20 \mathrm{mmHg}$ underwent cardiopulmonary resuscitation and were in cardiogenic shock $(A)$.

or acute-on-chronic presentation ( $-0.38 \pm 0.14$ vs. $-0.27 \pm 0.23$, $P=0.24$ ). At baseline echocardiography, moderate to severe systolic right ventricular dysfunction was present in all patients with high-risk and $80 \%$ of patients with intermediate-risk PE. After USAT, $10 \%$ of patients with high-risk PE and $18 \%$ of patients with intermediaterisk $\mathrm{PE}$ had moderate to severe systolic right ventricular dysfunction ( $P<0.01$ compared with baseline exam for both groups).

\section{Discussion}

In the present study, fixed low-dose USAT for patients with high- and intermediate-risk PE improved right ventricular function based on invasive pulmonary artery pressure and $\mathrm{CO}$ measurements and was associated with low bleeding and mortality rates.

The goal of revascularization therapy is to facilitate right ventricular recovery, to increase systemic perfusion, to improve symptoms and survival, and to prevent chronic thrombo-embolic pulmonary hypertension., ${ }^{3,7}$ Previous studies reported a reduction of the pulmonary thrombus load following USAT. ${ }^{11,12,19}$ However, reduction in clot burden may not necessarily cause an improvement in right ventricular function and haemodynamic parameters. ${ }^{20}$ In a recent study by Kennedy et al. ${ }^{13}$ of 60 patients with PE, USAT using varying rt-PA dose and treatment duration improved pulmonary artery pressure at completion of treatment. The total rt-PA dose was nearly twice as high as in our study (35 vs. $20 \mathrm{mg}$ ). Cardiac risk stratification was not routinely performed, and several patients without right ventricular dilatation were treated. In addition, mean pulmonary artery pressure was lower than in the present study ( $27 \mathrm{vs.} 37 \mathrm{mmHg}$ ). A novelty of our study is that a fixed low-dose thrombolysis regimen (total rt-PA dose $20 \mathrm{mg}$ over $15 \mathrm{~h}$ ) was used. Biomarker or imaging evidence of right ventricular dysfunction confirmed the presence of high- or intermediate-risk PE in all treated patients. In the present study, the reduction of pulmonary artery pressure was accompanied by an increase in cardiac index which suggests a reduction in pulmonary vascular resistance. In a randomized, controlled trial comparing a 2-h systemic infusion of rt-PA (total dose of $100 \mathrm{mg}$ ) to a double bolus of 10 units reteplase at an interval of $30 \mathrm{~min}$ in patients with high-risk PE, Tebbe et al. ${ }^{21}$ reported an increase of cardiac index of $\sim 30 \%$ in both groups within $24 \mathrm{~h}$. This corresponds well to the 33 and $42 \%$ increase in cardiac index after USAT in our patients with intermediate- and high-risk PE, respectively.

The long-term benefit of early haemodynamic improvement following catheter-based or systemic PE thrombolysis is less well established. Ribeiro et al. ${ }^{22}$ previously reported that after PE, pulmonary artery pressure progressively decreases during the first 30 days, followed by a stable phase. During 5 years of follow-up, only patients with persistent pulmonary hypertension during the stable phase required pulmonary thromboendarterectomy due to progressive right ventricular failure. ${ }^{22}$ In a randomized, controlled trial of systemic thrombolysis vs. anticoagulation alone, there was persistent improvement in echocardiographic parameters of right ventricular function throughout a 6-month follow-up in favour of the patients who underwent thrombolysis. ${ }^{23}$ In another randomized, controlled trial of systemic urokinase vs. heparin alone, pulmonary artery pressure and pulmonary vascular resistance at rest and during exercise at 7-year follow-up were lower in the thrombolysis group. ${ }^{24}$ Overall, it is reasonable to suggest that a revascularisation strategy with early improvement in haemodynamic parameters may potentially reduce the incidence of chronic pulmonary hypertension, the main longterm complication of PE.

An increased RV/LV ratio by echocardiography or CT angiography as a sign of right ventricular dysfunction predicts short-term mortality. ${ }^{5,25}$ Not surprisingly, changes in RV/LV ratio have been used as surrogate marker for clinical outcomes in the treatment of $\mathrm{PE}{ }^{12,26} \mathrm{~A}$ recent study found a significant reduction of the RV/LV ratio by $C T$ angiography from $1.33 \pm 0.24$ to $1.00 \pm 0.13$ following USAT. No fixed-dose thrombolysis regimen was used in this study and the total mean rt-PA dose was higher $(33.5 \pm 15.5 \mathrm{mg})$ with longer infusion time (mean duration $19.7 \pm 8.1 \mathrm{~h}$ ) than in our study. ${ }^{12} \mathrm{~A}$ similar treatment effect for systemic thrombolysis was also observed in the randomized controlled Tenecteplase Italian Pulmonary Embolism trial, comparing weight-adjusted intravenous tenecteplase vs. standard therapy with unfractionated heparin without thrombolysis in 
patients with intermediate-risk PE. The RV/LV ratio decreased from 1.36 at baseline to 1.04 over $24 \mathrm{~h}$ in the tenecteplase group while, in the control group, no significant reduction of the RV/LV ratio was observed $(1.32-1.22) .{ }^{26}$ Overall, a similar reduction in RV/LV ratio by $\sim 0.3$ was achieved after full-dose systemic thrombolysis and in our USAT subgroup of patients with serial echocardiographic imaging.

There is a great need for alternative revascularization strategies that are safer than systemic thrombolysis. The rate of major bleeding complications after systemic thrombolysis has been reported as high as $20 \%$, with intracranial haemorrhage in up to $3 \%{ }^{1,27}$ The risk of bleeding complications with systemic thrombolysis has recently been confirmed in the large randomized controlled Pulmonary Embolism International Thrombolysis trial comparing a single, weight-adapted intravenous bolus of tenecteplase with standard anticoagulation alone in patients with intermediate-risk PE. ${ }^{28} \mathrm{Al}-$ though a reduction in the combined primary endpoint of all-cause mortality and haemodynamic collapse was shown with tenecteplase, the rate of major bleeding was as high as $11.5 \%$, with $2 \%$ haemorrhagic strokes. ${ }^{29}$ It is not surprising that potentially life-saving systemic thrombolysis was withheld in two thirds of patients with high-risk PE. ${ }^{30,31}$ According to a recent publication by Stein et $a .^{32}$ the proportion of unstable PE patients receiving thrombolytic therapy decreased from 1999 to 2008 from 40 to 23\%. Although the present study is relatively small, it is reassuring that no fatal bleeding complication and particularly no intracranial haemorrhage occurred. More research is needed to investigate the safety of fixed low-dose local thrombolysis.

It has been suggested that patients with the most severe presentation and the highest risk of dying might gain the most from thrombolysis. ${ }^{8}$ In our study, improvement in haemodynamic parameters after USAT was the greatest in patients with high-risk PE and in those with a symptom duration of $<14$ days.

Our study has several limitations. Although data collection was retrospective, we established a standardized catheter intervention procedure with a fixed low-dose thrombolysis regimen prior to the study. Although most patients with intermediate- and high-risk PE presenting to our institution were treated by USAT, selection bias may have contributed to the favourable outcome observed in our study. Baseline and 24-h echocardiography exams were not available for analysis in more than half of the patients. We were not able to assess the full spectrum of echocardiographic parameters of right ventricular dysfunction, including tricuspid annular systolic excursion, lateral annular tissue Doppler, or right ventricular strain. However, all patients had complete haemodynamic datasets pre- and post-USAT. We investigated invasive haemodynamic measurements at baseline and at $15 \mathrm{~h}$ but were unable to provide haemodynamic data during the first hours of treatment. Although our study confirmed haemodynamic improvement in patients with high-risk PE at completion of treatment, it remains unclear if USAT rapidly improves haemodynamic parameters in these patients. Local administration of a thrombolytic bolus at the time of catheter placement prior to the initiation of USAT may have contributed to the favourable haemodynamic response in our patients with high-risk PE. Both systemic thrombolysis and surgical embolectomy rapidly improve haemodynamic parameters in unstable patients, and therefore remain preferred treatment modalities in this setting. ${ }^{8,33} \mathrm{CO}$ calculations were based on the Fick principle using assumed oxygen uptake, in addition, changes in fluid administration and inotropic support might have affected haemodynamic measurements. The classification of acute PE with symptom duration of $<14$ days is debatable, and symptom duration may be a poor indicator of PE onset. Of note, current consensus guidelines do not restrict the administration of thrombolytic therapy to patients with symptom duration of $<14$ days. ${ }^{3,8}$ We found somewhat greater haemodynamic improvement in patients with a symptom duration of $<14$ days when compared with patients with longer symptom duration; however, our study did not allow to assess the effect of symptom duration or delay in the initiation of treatment on haemodynamic parameters. The dose and duration of the used thrombolytic regimen (20 mg rt-PA during $15 \mathrm{~h}$ ) was arbitrary. In a recent randomized trial of patients with intermediate-risk PE, this regimen significantly improved right ventricular enlargement at $24 \mathrm{~h}$ in comparison to treatment with heparin alone. ${ }^{34}$ Finally, the contribution of ultrasound to the CDT effect remains unclear. An ongoing randomized controlled trial in patients with ilio-femoral deep vein thrombosis aims to quantify the effect of adding ultrasound to fixed low-dose local thrombolysis by using the venographic reduction in thrombus burden from baseline to $15 \mathrm{~h}$ (NCT01482273).

In conclusion, our study results suggest that fixed low-dose USAT rapidly reverses haemodynamic impairment in patients with high-and intermediate-risk PE. Major bleedings, in particular intracranial haemorrhages, seem to be less frequent with this treatment regimen than with systemic thrombolysis. Future studies will further define the role of USAT in comparison to anticoagulation alone and to other revascularization strategies in the management of PE patients at increased risk.

Conflict of interest: N.K. is a consultant for EKOS Corporation. All other authors report no conflict of interest.

\section{References}

1. Goldhaber SZ, Visani L, De Rosa M. Acute pulmonary embolism: clinical outcomes in the international cooperative pulmonary embolism registry (ICOPER). Lancet 1999; 353:1386-1389

2. Torbicki A, Perrier A, Konstantinides S, Agnelli G, Galie N, Pruszczyk P, Bengel F, Brady AJ, Ferreira D, Janssens U, Klepetko W, Mayer E, Remy-Jardin M, Bassand JP. Guidelines on the diagnosis and management of acute pulmonary embolism: the task force for the diagnosis and management of acute pulmonary embolism of the European Society of Cardiology (ESC). Eur Heart J 2008;29:2276-2315.

3. Jaff MR, McMurtry MS, Archer SL, Cushman M, Goldenberg N, Goldhaber SZ, Jenkins JS, Kline JA, Michaels AD, Thistlethwaite P, Vedantham S, White RJ, Zierler BK. Management of massive and submassive pulmonary embolism, iliofemoral deep vein thrombosis, and chronic thromboembolic pulmonary hypertension: a scientific statement from the American Heart Association. Circulation 2011; 123:1788-1830.

4. Kasper W, Konstantinides S, Geibel A, Olschewski M, Heinrich F, Grosser KD, Rauber K, Iversen S, Redecker M, Kienast J. Management strategies and determinants of outcome in acute major pulmonary embolism: results of a multicenter registry. J Am Coll Cardiol 1997;30:1165-1171.

5. Fremont B, Pacouret G, Jacobi D, Puglisi R, Charbonnier B, de Labriolle A. Prognostic value of echocardiographic right/left ventricular end-diastolic diameter ratio in patients with acute pulmonary embolism: results from a monocenter registry of 1,416 patients. Chest 2008;133:358-362.

6. Kucher N, Rossi E, De Rosa M, Goldhaber SZ. Massive pulmonary embolism. Circulation 2006;113:577-582.

7. Engelberger RP, Kucher N. Catheter-based reperfusion treatment of pulmonary embolism. Circulation 2011;124:2139-2144.

8. Kearon C, Akl EA, Comerota AJ, Prandoni P, Bounameaux H, Goldhaber SZ, Nelson ME, Wells PS, Gould MK, Dentali F, Crowther M, Kahn SR. Antithrombotic therapy for VTE disease: antithrombotic therapy and prevention of thrombosis, 9th 
ed: American college of chest physicians evidence-based clinical practice guidelines. Chest 2012;141:e419S-e494S.

9. Braaten JV, Goss RA, Francis CW. Ultrasound reversibly disaggregates fibrin fibers. Thromb Haemost 1997;78:1063-1068.

10. Siddiqi F, Odrljin TM, Fay PJ, Cox C, Francis CW. Binding of tissue-plasminogen activator to fibrin: effect of ultrasound. Blood 1998;91:2019-2025.

11. Lin PH, Annambhotla S, Bechara CF, Athamneh H, Weakley SM, Kobayashi K, Kougias P. Comparison of percutaneous ultrasound-accelerated thrombolysis versus catheter-directed thrombolysis in patients with acute massive pulmonary embolism. Vascular 2009;17(Suppl 3):S137-S147.

12. Engelhardt TC, Taylor AJ, Simprini LA, Kucher N. Catheter-directed ultrasound-accelerated thrombolysis for the treatment of acute pulmonary embolism. Thromb Res 2011;128:149-154.

13. Kennedy RJ, Kenney HH, Dunfee BL. Thrombus resolution and hemodynamic recovery using ultrasound-accelerated thrombolysis in acute pulmonary embolism.J Vasc Interv Radiol 2013;24:841-848.

14. Quiroz R, Kucher N, Schoepf UJ, Kipfmueller F, Solomon SD, Costello P, Goldhaber SZ. Right ventricular enlargement on chest computed tomography: prognostic role in acute pulmonary embolism. Circulation 2004;109:2401-2404.

15. Araoz PA, Gotway MB, Harrington JR, Harmsen WS, Mandrekar JN. Pulmonary embolism: prognostic CT findings. Radiology 2007;242:889-897.

16. Ribeiro A, Lindmarker P, Juhlin-Dannfelt A, Johnsson H, Jorfeldt L. Echocardiography Doppler in pulmonary embolism: right ventricular dysfunction as a predictor of mortality rate. Am Heart J 1997;134:479-487.

17. Fritts HW, Cournand A. The application of the fick principle to the measurement of pulmonary blood flow. Proc Natl Acad Sci USA 1958;44:1079-1087.

18. Schulman $S$, Kearon C. Definition of major bleeding in clinical investigations of antihemostatic medicinal products in non-surgical patients. J Thromb Haemost 2005;3: 692-694.

19. Chamsuddin A, Nazzal L, Kang B, Best I, Peters G, Panah S, Martin L, Lewis C, Zeinati C, HoJW, Venbrux AC. Catheter-directed thrombolysis with the endowave system in the treatment of acute massive pulmonary embolism: a retrospective multicenter case series. J Vasc Interv Radiol 2008;19:372-376.

20. Cuculi F, Kobza R, Bergner M, Erne P. Usefulness of aspiration of pulmonary emboli and prolonged local thrombolysis to treat pulmonary embolism. Am J Cardiol 2012; 110:1841-1845.

21. Tebbe U, Graf A, Kamke W, Zahn R, Forycki F, Kratzsch G, Berg G. Hemodynamic effects of double bolus reteplase versus alteplase infusion in massive pulmonary embolism. Am Heart J 1999;138:39-44.

22. Ribeiro A, Lindmarker P, Johnsson H, Juhlin-Dannfelt A, Jorfeldt L. Pulmonary embolism: one-year follow-up with echocardiography doppler and five-year survival analysis. Circulation 1999;99:1325-1330.
23. Fasullo S, Scalzo S, Maringhini G, Ganci F, Cannizzaro S, Basile I, Cangemi D, Terrazzino G, Parrinello G, Sarullo FM, Baglini R, Paterna S, Di Pasquale P. Six-month echocardiographic study in patients with submassive pulmonary embolism and right ventricle dysfunction: comparison of thrombolysis with heparin. Am J Med Sci 2011; 341:33-39.

24. Sharma GV, Folland ED, McIntyre KM, Sasahara AA. Long-term benefit of thrombolytic therapy in patients with pulmonary embolism. Vasc Med 2000;5:91-95.

25. SchoepfUJ, Kucher N, Kipfmueller F, Quiroz R, Costello P, Goldhaber SZ. Right ventricular enlargement on chest computed tomography: a predictor of early death in acute pulmonary embolism. Circulation 2004;110:3276-3280.

26. Becattini C, Agnelli G, Salvi A, Grifoni S, Pancaldi LG, Enea I, Balsemin F, Campanini M, Ghirarduzzi A, Casazza F. Bolus tenecteplase for right ventricle dysfunction in hemodynamically stable patients with pulmonary embolism. Thromb Res 2010;125: e82-e86.

27. Fiumara K, Kucher N, Fanikos J, Goldhaber SZ. Predictors of major hemorrhage following fibrinolysis for acute pulmonary embolism. Am J Cardiol 2006;97: 127-129.

28. Single-bolus tenecteplase plus heparin compared with heparin alone for normotensive patients with acute pulmonary embolism who have evidence of right ventricular dysfunction and myocardial injury: rationale and design of the Pulmonary Embolism Thrombolysis (PEITHO) trial. Am Heart J 2012;163:33-38.

29. Konstantinides $\mathrm{S}$. On behalf of the peitho investigators. Fibrinolysis for normotensive patients with acute submassive pulmonary embolism. In: Presented at the annual meeting of the american college of cardiology on march 9, 2013.

30. Spirk D, Husmann M, Hayoz D, Baldi T, Frauchiger B, Engelberger R, Amann-Vesti B, Baumgartner I, Kucher N. Predictors of in-hospital mortality in elderly patients with acute venous thrombo-embolism: the Swiss venous thromboembolism registry (SWIVTER). Eur Heart J 2011;33:921-926.

31. Lin BW, Schreiber DH, Liu G, Briese B, Hiestand B, Slattery D, Kline JA, Goldhaber SZ, Pollack CV Jr. Therapy and outcomes in massive pulmonary embolism from the emergency medicine pulmonary embolism in the real world registry. Am J Emerg Med 2012;30:1774-1781.

32. Stein PD, Matta F. Thrombolytic therapy in unstable patients with acute pulmonary embolism: saves lives but underused. Am J Med 2012;125:465-470.

33. Kadner A, Schmidli J, Schonhoff F, Krahenbuhl E, Immer F, Carrel T, Eckstein F. Excellent outcome after surgical treatment of massive pulmonary embolism in critically ill patients. J Thorac Cardiovasc Surg 2008;136:448-451.

34. Kucher N, Boekstegers P, Muller O, Kupatt C, Beyer-Westendorf J, Heitzer T, Tebbe U, Horstkotte J, Muller R, Blessing E, Greif M, Lange P, Hoffmann RT, Werth S, Barmeyer A, Hartel D, Grunwald H, Empen K, Baumgartner I. Randomized controlled trial of ultrasound-assisted catheter-directed thrombolysis for acute intermediate-risk pulmonary embolism. Circulation 2013;129:479-86. 